\title{
EsTUdIRS DE FILDSRFíA 5
}

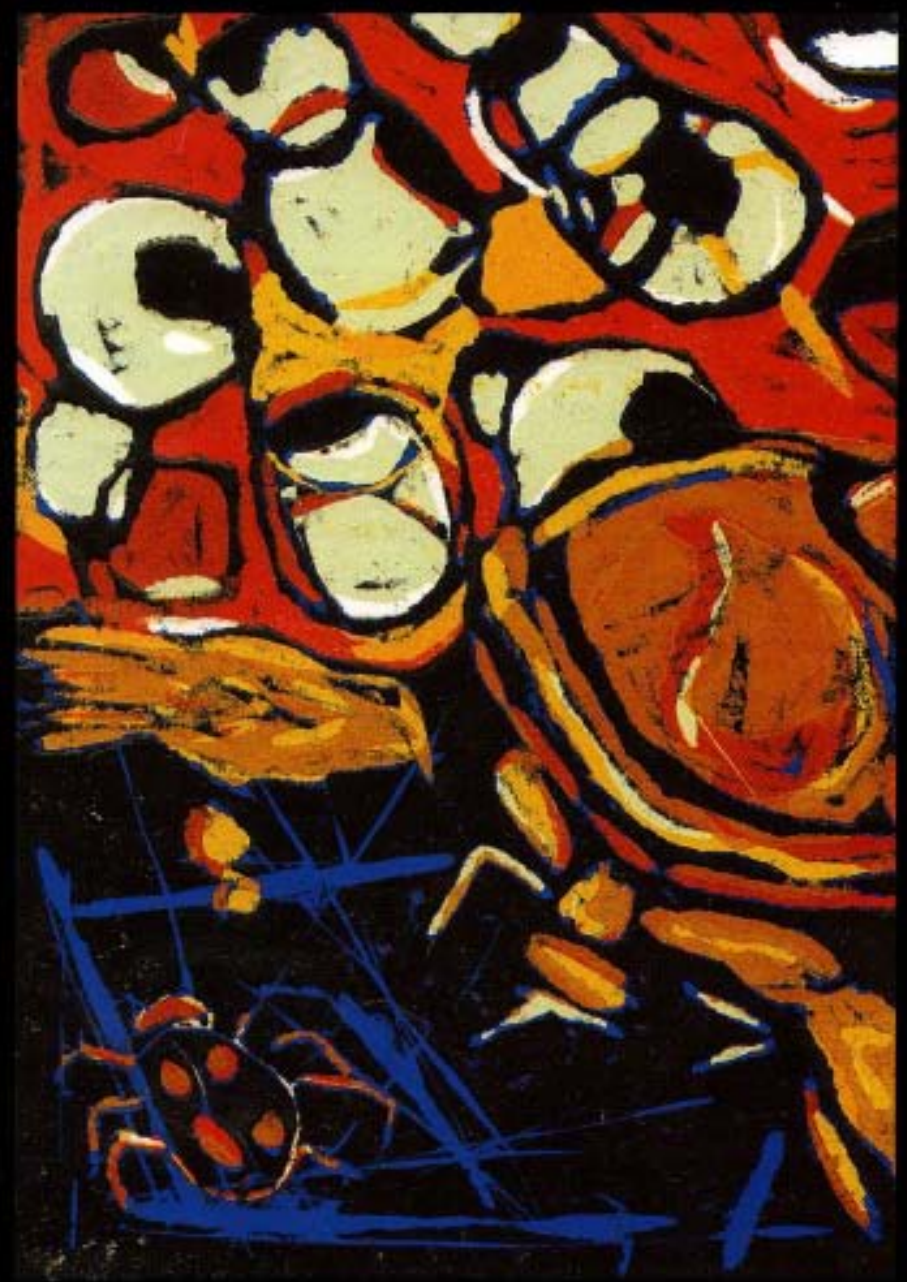




\section{CRISIS EPISTEMOLÓGICAS, NARRATIVA DRAMÁTICA Y FILOSOFIA DE LA CIENCIA: \\ Alasdair Mcintyre \\ University of Notre Dame}

¿Qué es una crisis epistemológica? Consideremos, primero, la situación de agentes ordinarios que viven tales crisis. Alguien que creía ser muy estimado por sus empleadores y colegas es repentinamente despedido; alguien propuesto para la membresía de un club cuyos miembros, él creía, eran todos amigos cercanos, es rechazado. O alguien se enamora y necesita saber qué siente realmente su amado: alguien deja de estar enamorado y necesita saber cómo es que él o ella pudo haber estado tan errado respecto al otro. Para todas esas personas la relación de parecer a ser se vuelve crucial. Es en tales situaciones que agentes ordinarios que nada han aprendido jamás acerca de filosofía académica están aptos para redescubrir por sí mismos versiones del problema de las otras mentes y del problema de la justificación de la inducción. Es decir, descubren que hay un problema en torno a la justificación racional de las inferencias que van desde premisas acerca del comportamiento de otras personas hasta conclusiones acerca de sus pensamientos, sentimientos y actitudes, y de las inferencias que van desde premisas acerca de cómo los individuos han actuado en el pasado hasta conclusiones expresadas como generalizaciones acerca de su comportamiento -generalizaciones que nos permitirian hacer predicciones razonablemente confiables acerca de su comportamiento futuro. Lo que ellos consideraron una evidencia que apuntaba claramente en alguna dirección, resulta siendo ahora susceptible de interpretaciones antagónicas. Tal descubrimiento es frecuentemente paralizante, y si todo el tiempo hubiésemos de tener en cuenta la multiplicidad de posibles interpretaciones abiertas a nosotros, la vida social dificilmente podría continuar tal como la conocemos. Pues la vida social se sustenta en asumir que somos, en gran medida, capaces de predecir el comportamiento de los otros - de modo que el error, el engaño, el autoengaño, la ironia y la ambigüedad, aunque omnipresentes en la vida social, no están lo bastante expandidos como para volver imposibles el razonamiento confiable y la acción razonable. Pero ¿puede de alguna manera justificarse el que asumamos esto?

Consideremos lo que significa compartir una cultura. Es compartir esquemas que son a uno y el mismo tiempo constitutivos de y normativos para la acción inteligible que realizo, y son también al mismo tiempo medios para la interpretación de las acciones de otros. Mi capacidad de entender lo que tú estás haciendo y mi capacidad de actuar de manera inteligible (tanto para mi mismo como para otros) son una y la misma capacidad. Es verdad que no puedo dominar esos esquemas sin adquirir tam-

\footnotetext{
- Este artículo fue originalmente publicado en: The Monist, №60, 1977, pp. 453-472 (N. E.).
} 
bién los medios para engañar, hacer bromas más o menos elaboradas, ejercitar la ironia y utilizar la ambigüedad. Pero es verdad también, e incluso más importante, que mi capacidad de conducir cualquier transacción exitosa depende de que me presente yo mismo ante la mayor parte de personas la mayor parte de tiempo de maneras no ambiguas, no irónicas, no engañosas e inteligibles. Son aquellos esquemas los que permiten hacer inferencias desde premisas del comportamiento pasado hacia conclusiones sobre el comportamiento futuro y actitudes internas presentes. No son ciertamente, generalizaciones empíricas, son prescripciones para la interpretación. Pero aunque son ellas las que normalmente nos preservan de la presión del problema de otras mentes y del problema de la inducción, son ellas precisamente las que en ciertas circunstancias pueden conducirnos hacia esos mismos problemas.

Pues no se trata tan sólo de que un individuo pueda confiar en los esquemas que hasta ahora han dado forma a sus interpretaciones de la vida social, para luego encontrar que él o ella han sido arrastrados por el error o el engaño radicales, de tal manera que por primera vez los esquemas sean puestos en cuestión -quizá también por primera vez se vuelven visibles al individuo que los emplea. También puede suceder que el individuo llegue a reconocer que es posible elaborar interpretaciones sistemáticamente diferentes, que pueden existir esquemas rivales y alternativos que produzcan visiones mutuamente incompatibles de lo que sucede a su alrededor. Esta es justamente la forma de las crisis epistemológicas que enfrentan los agentes ordinarios y es notable que no haya visión alguna de ésta en algún lugar de la literatura de la filosofía académica. Quizá es un síntoma importante de la condición de tal

84 disciplina. Pero felizmente poseemos un estudio clásico de tales crisis. Es el Hamlet de Shakespeare.

Hamlet regresa de Wittenberg con muchos esquemas disponibles para interpretar los eventos en Elsinore de los cuales ya forma parte. Está el esquema de venganza de las sagas nórdicas; está el esquema del renacimiento cortesano; hay un esquema maquiavélico (en el sentido literal del término) acerca de la competición por el poder. Pero este personaje no sólo tiene el problema de cuál esquema aplicar: también tiene el otro problema ordinario del agente: ¿a quién ha de creer? ¿a su madre? ¿a Rosenkrantz y Guildestern? ¿al fantasma de su padre? Hasta que haya adoptado algún esquema, no sabrá qué considerar como evidencia. Hasta que sepa qué tomar como evidencia no puede decidir cuál esquema adoptar. Atrapado en esta circularidad epistemológica, la forma general de su problema es: "¿qué sucede aquí?" De esta manera, el problema de Hamlet es similar al que enfrentan los críticos literarios cuando se preguntan: "¿qué sucede en Hamlet?" Y es también similar al de los directores cuando se preguntan: "¿qué se debería dejar de lado y qué debería incluirse en mi producción de tal manera que mi audiencia pueda entender qué sucede en Hamlet?"

Es importante notar esta semejanza entre el problema de Hamlet y los problemas de críticos y directores, porque sugiere que ambos están planteando una cuestión que podría ser igualmente formulada como: "¿qué sucede en Hamlet?" o "¿cómo debería ser construida la narrativa de esos eventos?" El problema de Hamlet surge porque la narrativa dramática de su familia y del reino de Dinamarca, mediante la cual iden- 
tifica su propio lugar en la sociedad y sus relaciones con otros, ha sido resquebrajada por dudas interpretativas radicales. Su labor es reconstituir, reescribir esta narrativa, revertiendo su comprensión de eventos pasados a la luz de las respuestas actuales a su indagación. Esta indagación está formada por dos ideales, verdad $\theta$ inteligibilidad. y la persecución de ambas no siempre es fácilmente conciliable. El descubrimiento de una verdad hasta ahora insospechada es justamente lo que puede resquebrajar una visión hasta ahora inteligible. Y ciertamente, mientras Hamlet intenta descubrir una narrativa verdadera e inteligible de los eventos que comprometen a sus padres y a Claudius, Gertrude y Claudius intentan descubrir una narrativa verdadera e inteligible de la investigación de Hamlet. Ser incapaz de hacerse inteligible a uno mismo es arriesgarse a ser tomado por un loco, es, si lo llevamos lo suficientemente lejos. estar loco. Y la locura o la muerte son siempre las consecuencias que la resolución de una crisis epistemológica evita, puesto que una crisis epistemológica es siempre una crisis en las relaciones humanas.

Cuando se resuelve una crisis epistemológica, la construcción de una nueva narrativa es lo que permite al agente entender tanto cómo él o ella pudieron haber sostenido inteligiblemente las creencias que originariamente sostenian, como el motivo por el cual él o ella pudieron haber sido tan drásticamente engañados por éstas. La narrativa en cuyos términos él o ella en un principio ordenaron sus experiencias está construida a su vez al interior del tema de una narrativa más amplia. El agente ha llegado a entender cómo los criterios de verdad y comprensión deben ser reformulados. Hubo de volverse epistemológicamente autoconsciente, y en un cierto punto puede llegar a dos conclusiones: la primera es que sus nuevas formas de comprensión pueden llegar a su vez a ser puestas en cuestión en algún momento; la segunda es que, dado que en tales crisis los criterios de verdad, inteligibilidad y racionalidad pueden ellos mismos ser puestos en cuestión -tal como lo son en el Hamlet- no estamos en condiciones de sostener que ahora poseemos la verdad o somos totalmente racionales. Lo más que podemos sostener es que ésta es la mejor visión que alguien ha sido capaz de dar hasta ahora, y que nuestras creencias acerca de cuáles son los rasgos de una 'mejor visión hasta ahora' cambian de maneras que son impredecibles en el presente.

Los filósofos frecuentemente han estado preparados para reconocer este carácter histórico respecto de las teorias científicas, pero generalmente han deseado exceptuar su propio pensamiento de tal historicidad. Lo mismo ocurre, ciertamente, con muchos escritores de narrativa dramática. Hamlet es única entre las obras dramáticas en cuanto a su apertura a la reinterpretación. Consideremos, por contraste, el procedimiento de Jane Austen en Emma. Emma insiste en considerar a su protegée. Harriet, como un personaje de romance del siglo dieciocho. Ella la dota, engañándose a si misma y a Harriet, con las cualidades convencionales de la heroína de tales romances. El parentesco de Harriet es desconocido: Emma la convierte en la expósita heroína de nacimiento aristocrático tan común en tales romances. Y ella diseña para Harriet precisamente el final feliz de tales romances, el matrimonio con un ser superior. Al final de Emma, Jane Austen ha dotado a Emma de alguna comprensión de lo que en ella misma la llevó a no percibir lo erróneo de su interpretación del mundo en términos de romance. Emma se ha vuelto una narrativa acerca de la 
narrativa. Pero Emma, aunque experimente una transformación moral, tiene tan sólo una crisis epistemológica menor, dado que el punto de vista que ha llegado a adoptar, gracias a la intervención de Mr. Knigthly, es presentado como si fuese un punto de vista desde el cual puede ser visto el mundo tal cual es. La interpretación falsa no ha sido reemplazada por una interpretación más adecuada que pueda algún día ser trascendida, sino simplemente por la verdad. Ciertamente podemos ver que Jane Austen está meramente reemplazando una interpretación por otra, pero la propia Jane Austen no alcanza a reconocer esto. privando asi también a Emma de este reconocimiento.

Usualmente los filósofos han sido Emmas y no Hamlets, excepto en cuanto a que en un aspecto han sido frecuentemente menos perceptivos que Emma. Pues para Emma está claro que su movimiento hacia la verdad necesariamente tiene una dimensión moral. Ni Platón ni Kant dudarian de esto. Pero la historia de la epistemología, como la historia de la ética, es usualmente escrita como si no fuese una narrativa moral, esto es, como si de hecho ésta no fuese una narrativa. Pues la narrativa requiere de una estructura evaluativa en la cual los buenos o malos personajes ayudan a producir resultados desafortunados o felices.

Nos falta notar otro aspecto de las narrativas y su rol en las crisis epistemológicas. He sugerido que el progreso epistemológico consiste en la construcción y reconstrucción de narrativas y formas de narrativas más adecuadas, y que las crișis epistemológicas son ocasiones para tal reconstrucción. Pero si éste fuese realmente el caso, entonces 86 dos tipos de pregunta necesitarían respuesta. La primera sería del tipo: ¿cómo comienza este progreso? ¿Cuáles son las narrativas desde las cuales empezamos? La segunda: ¿cómo así entonces, resulta no sólo que a la narrativa le han dado tan pequeño lugar pensadores como Descartes y en adelante, sino que antes y después ha sido frecuentemente tratada meramente como una forma estética? Las respuestas a estas preguntas no están enteramente desconectadas.

Comencemos desde el mito, no sólo desde los mitos de los pueblos primitivos, sino desde esos mitos o cuentos de hadas esenciales para una niñez bien llevada. Bruno Bettelheim ha escrito: "Antes y dentro ya del periodo edípico (aproximadamente. entre los tres y los seis o siete años), la experiencia del mundo que tiene el niño es caótica. (...) Durante y debido a las contiendas edípicas, el mundo externo empieza a tener más significado para el niño, que empieza a intentar darle sentido... Mientras un niño escucha un cuento de hadas, encuentra ideas acerca de cómo puede crear un orden del caos que es su vida interna"' . Es desde los cuentos de hadas, sostiene Bettelheim, que el niño aprende cómo comprometerse con, y percibir un orden en una realidad social; $y$ el niño al que se le priva del tipo correcto de cuentos de hadas en la edad correcta será proclive a adoptar estrategias para evadir una realidad que no ha aprendido cómo interpretar o manipular.

\footnotetext{
' Bruno Bettelheim. The Uses of Enchantment, Nueva York: Alfred A. Knopf, 1976, pp. 74 - 75.
} 
"El niño se pregunta, ¿¿Quién soy? ¿De dónde vengo? ¿Cómo llegó a existir el mundo? ¿Quién creó al hombre y a todos los animales? ¿Cuál es el propósito de la vida?'... Se pregunta qué o quién arroja la adversidad sobre él, y qué puede protegerlo de ella. ¿Hay poderes benevolentes además de sus padres? ¿Son sus padres poderes benevolentes? ¿Cómo debería educarse él, y por qué? ¿Hay esperanza para él, aunque pudiese haber hecho algo malo? ¿Por qué le sucede a él todo esto? ¿Qué significará esto para su futuro?"2 Inicialmente el niño requiere respuestas que sean verdaderas para su propia experiencia, pero también es cierto que llega a prender la inadecuación de tal experiencia. Bettelheim señala que el niño pequeño al que los adultos le cuentan que el mundo es un globo suspendido en el espacio girando a increible velocidad puede sentirse conminado a repetir lo que le dicen, pero encontraría inmensamente más plausible que se le diga que la tierra es sostenida por un gigante. Pero con el tiempo el niño pequeño aprende que lo que los adultos le contaron es cierto. Tal niño puede convertirse en un Descartes, alguien que siente que todas las narrativas son fábulas engañosas comparadas con lo que ahora considera la sólida verdad de la física.

Hacer surgir la cuestión de la verdad no conlleva necesariamente al rechazo del mito o de la historia como la forma apropiada, y quizás como la única forma apropiada. en que ciertas verdades pueden ser contadas. El niño podría volverse no un Descartes, sino un Vico o un Hamann que escriba una historia acerca de cómo hubo de escapar de la influencia que ejercieron originalmente en él las historias de su niñez y las historias de la niñez de la raza humana, en vistas a descubrir cómo es que las historias pueden ser historias verdaderas. Tal narrativa será ella misma una historia de transiciones epistemológicas y esta narrativa puede muy bien ser llevada a un punto en el cual las preguntas son impuestas al narrador, lo cual le imposibilita el continuar usándola como instrumento de interpretación. Tal cosa, ciertamente, le sucedió a Descartes, quien habiendo abjurado de la historia como un medio de verdad, nos relata su propia historia como el medio a través del cual se lleva adelante la búsqueda de verdad. Para Descartes y para otros es en este momento que ocurre una crisis epistemológica. $Y$ todas aquellas cuestiones que el niño preguntó a quien le contó los cuentos de hadas resurgen en una nueva forma adulta. La filosofía apunta ahora a la misma tarea que una vez tuvo el mito.

La descripción que hace Descartes de su propia crisis epistemológica tuvo, ciertamente, una influencia única. Y esto a pesar de que describe de modo radicalmente erróneo su propia crisis, y ciertamente ha mostrado ser una guía altamente errónea sobre la naturaleza de las crisis epistemológicas en general. El agente que atraviesa una crisis epistemológica sabe algo muy importante: que un esquema de interpretación en el que hasta ahora habia confiado se ha derrumbado irremediablemente de ciertas maneras muy especificas. Así sucede con Hamlet. Descartes, si embargo, empieza asumiendo que nada sabe hasta que pueda descubrir un primer principio

2 Ibid., p. 47. 
libre de presupuestos, sobre el cual todo lo demás pueda ser fundado. Las dudas de Hamlet están formuladas contra un background de las que él considera-correctamente-creencias bien fundadas; la duda cartesiana pretende prescindir de cualquier background. Ha de ser una duda sin contexto. Surge por lo tanto también la tradición de enseñanza filosófica que presupone que las dudas cartesianas pueden ser comprendidas por cualquiera en cualquier momento o lugar. Pero alguien que realmente creyese que nada sabe ni siquiera sabria cómo comenzar con la duda radical: puesto que no tendría concepción alguna de cuál podría ser su tarea, de qué sería acallar sus dudas y adquirir creencias bien fundadas. Inversamente, alguien que sabe lo suficiente como para saber eso, posee ya un conjunto de creencias epistemológicas que no pone en duda.

El error de Descartes es complejo. Primero que todo, él no reconoce que entre los rasgos del universo que no está poniendo en duda está su propia capacidad no sólo de usar el francés y el latín, sino incluso de expresar el mismo pensamiento en ambos lenguajes; y como consecuencia no pone en duda lo que ha heredado en y con esos lenguajes, a saber, una manera de ordenar tanto el pensamiento como el mundo expresada en un conjunto de significados. Esos significados tienen una historia - el latín del siglo XVII lleva la marca de haber sido el lenguaje de la escolástica, tal como la escolástica misma estaba marcada por la influencia del latín de los siglos XII y XIII. Fue quizás porque la presencia de sus lenguajes era invisible al Descartes del Discours y de las Meditationes que no nota lo que Gilson señala detalladamente: cuánto de lo que él consideró la reflexión espontánea de su mente era de hecho 88 una repetición de sentencias y frases de sus textos de escuela. Incluso el cogito se encuentra ya en San Agustín.

Lo que no reconoce Descartes es la presencia no sólo del lenguaje, sino de una tradición - tradición a la que cree haber renunciado exitosamente. Fue de la tradición que heredó sus ideales epistemológicos. Pues en el núcleo de esta tradición estaba la concepción del conocimiento como análogo a la visión: el ojo de la mente contempla sus objetos a la luz de la razón. Al mismo tiempo esta tradición desea contrastar marcadamente conocimiento y experiencia sensible, incluyendo la experiencia visual. Hay, por lo tanto, una incoherencia metafórica en el corazón de toda teoría del conocimiento en esta tradición platónica y agustiniana, incoherencla que Descartes inconscientemente reproduce. Asi, Descartes tampoco puede reconocer que está respondiendo no sólo a las intemporales demandas del escepticismo, sino a una crisis sumamente específica en una particular tradición social e intelectual.

Uno de los signos de que una tradición está en crisis es que sus maneras acostumbradas de relacionar parecer y ser comienzan a desplomarse. De este modo, las presiones del escepticismo se vuelven más urgentes, y los intentos por hacer lo imposible por refutar el escepticismo de una vez por todas, se vuelven proyectos de central importancia para la cultura y no meramente empresas académicas privadas. Esto fue lo que sucedió en la Edad Media tardía y en el siglo XVI. Modos heredados de ordenar la experiencia revelan muchas posibilidades rivales de interpretación. No es accidental el que haya una multiplicidad de interpretaciones rivales tanto del pensamiento como de la vida de figuras tales como Lutero y Maquiavelo, de una manera 
que no tiene equivalente en el caso de figuras igualmente ricas y complejas como las de Abelardo y Tomás de Aquino. La ambigüedad, la posibilidad de interpretaciones alternativas, se vuelve un rasgo central del carácter y la actividad humanos. Hamlet es el admirable espejo que Shakespeare elabora de su época, y la diferencia entre la visión de Shakespeare de la crisis epistemológica y la visión de Descartes está clara ahora. Shakespeare nos invita a reflexionar sobre la crisis del self como una crisis en la tradición misma que ha formado el self. Descartes, mediante su actitud hacia la historia y la fábula se ha quitado la posibilidad de reconocerse a sí mismo: ha inventado una auto-consciencia ahistórica auto-referida e intenta describir su crisis epistemológica en esos términos. Poco sorprende el que la describa mal.

Consideremos por contraste a Galileo. Cuando entró a la escena científica, confrontó mucho más que el conflicto entre la astronomía tolemaica y copernicana. El sistema tolemaico era en sí mismo inconsistente tanto con los ampliamente aceptados requerimientos platónicos para una astronomia verdadera, como con los quizás incluso más ampliamente aceptados principios de la física aristotélica. Estos últimos a su vez eran inconsistentes con los descubrimientos de dos siglos de los estudiosos de Oxford, Paris y Padua acerca del movimiento. No es sorprendente que el instrumentalismo haya florecido como filosofía de la ciencia y que el instrumentalismo de Osiander al leer a Copérnico no fuese más que la contraparte de las interpretaciones instrumentalistas tempranas del sistema tolemaico. El instrumentalismo, como intento de refutar el escepticismo, es un signo característico de una tradición en crisis.

Galileo resuelve la crisis por medio de una estrategia tripartita. Rechaza el instrumentalismo, reconcilia la astronomia y la mecánica, y redefine el lugar del experimento en la ciencia natural. La vieja visión mitológico-empirista consideraba que Galileo apelaba a los hechos contra Tolomeo y Aristóteles; lo que él realmente hizo fue dar una nueva visión de qué habria de ser apelar a los hechos. ¿Dónde reside la superioridad de Galileo respecto de sus predecesores? La respuesta es que él, por vez primera, permite que el trabajo de sus predecesores sea evaluado desde un conjunto común de estándares. Las contribuciones de Platón. Aristóteles, los estudiosos del Merton College, Oxford, y Padua, y finaimente los trabajos del propio Copérnico, todos por fin encajaban. O, para poner las cosas de una manera distinta pero equivalente: la historia de la ciencia medieval tardía podia finalmente ser presentada en una narrativa coherente. La obra de Galileo implica reescribir la narrativa que constituye la tradición científica. Ahora se vuelve posible distinguir en retrospectiva aquellas anomalias que habian sido genuinos contraejemplos para esas teorias aceptadas, de aquellas anomalias que podrian justificadamente ser evitadas por un artificio explicativo ad hoc o incluso ser ignoradas. También se vuelve posible ver en retrospectiva cómo los diversos elementos de teorías diversas se confrontan con otras teorias y con observaciones y experimentos, y entender cómo han sobrevivido llevando las marcas de aquellas confrontaciones. Una teoria siempre lleva las marcas de su paso a través del tiempo, y las teorías con las que Galileo se las tuvo que ver no son la excepción.

Déjenme presentar el punto de lo que quiero decir respecto a Galileo de una manera que, a primera vista, sea quizás paradójica. Tendemos a suponer que, dado que 
Galileo fue un científico particularmente grande, tiene por tanto su propio lugar peculiar en la historia de la ciencia. Yo sugiero más bien que dado su lugar peculiarmente importante en la historia de la ciencia él es considerado un científico particularmente grande. El criterio para una teoría exitosa es que nos permita entender a sus predecesores de una manera novedosamente inteligible. Esto, al mismo tiempo, nos permite entender con precisión por qué sus predecesores han de ser rechazados o modificados y por qué, sin y antes de su iluminación, la teoria pasada pudo conservar su credibilidad. Esta introduce nuevos estándares para evaluar el pasado. Remodela la narrativa que constituye la continua reconstrucción de la tradición científica.

Esta conexión entre narrativa y tradición casi no ha sido notada hasta ahora, quizás porque la tradición usualmente ha sido tomada en serio sólo por teóricos sociales conservadores. Aunque aquellos rasgos de la tradición que emergen como importantes cuando se comprende la conexión entre tradición y narrativa, son aquellos que los teóricos conservadores no tienen disposición para atender. Pues lo que constituye una tradición es un conjunto de conflictos de interpretaciones de tal tradición, conflicto que a su vez tiene una historia susceptible de interpretaciones rivales. Si soy un judio, por ejemplo, he de reconocer que la tradición del judaísmo está parcialmente constituida por una continua controversia acerca de lo que significa ser un judio. Supongamos que soy un americano: la tradición está parcialmente constituida por una continua controversia acerca de lo que significa ser un americano y parcialmente por una continua controversia acerca de lo que significa haber rechazado la tradición. Si soy un historiador, debo reconocer que la tradición de la 90 historiografía está parcialmente, aunque centralmente, constituida por controversias acerca de qué es la historia y qué debería ser, desde Hume y Gibbon hasta Namier y Edward Thompson. Notemos que los tres tipos de tradición -religiosa, política e intelectual- implican el debate epistemológico como un rasgo necesario de sus conflictos. Pues no se trata simplemente de que diferentes participantes en una tradición estén en desacuerdo; ellos también están en desacuerdo acerca de cómo caracterizar sus desacuerdos y cómo resolverlos. Están en desacuerdo acerca de qué constituye un razonamiento apropiado, una evidencia decisiva, una prueba concluyente.

Una tradición entonces no solamente incorpora la narrativa de un argumento, sino que sólo al ser recobrada por una redescripción argumentativa de tal narrativa estará ella misma en conflicto con otras redescripciones argumentativas. Cada tradición por tanto está siempre en peligro de caer en incoherencias y cuando una tradición lo hace a veces sólo puede ser recobrada por una reconstitución revolucionaria. Precisamente tal reconstitución de una tradición que ha caído en la incoherencia fue el trabajo de Galileo.

Ahora se hace obvio por qué introduje la noción de tradición aludiendo negativamente al punto de vista de los teóricos conservadores. Ellos, desde Burke en adelante, han querido contraponer tradición y razón, y tradición y revolución. No razón, sino prejuicio; no revolución, sino precedente heredado: esas son las oposiciones clave para Burke. Aun si los presentes argumentos son correctos, son sus tradiciones las que conllevan la razón, y las tradiciones en ciertos periodos requieren y necesitan revolu- 
ciones para su continuación. Burke vio la Revolución Francesa meramente como la derrota negativa de todo lo que Francia habia sido, y muchos conservadores franceses han coincidido con él, pero pensadores posteriores tan diferentes como Péguy y Hilaire Belloc fueron capaces de ver retrospectivamente la gran revolución como la reconstrucción de una Francia más antigua, de tal manera que Juana de Arco y Dantón pertenecen a la misma, si bien inmensamente compleja, tradición.

Surge el conflicto, ciertamente, no sólo al interior, sino entre tradiciones y tales conflictos ponen a prueba los recursos de cada tradición contendiente. Otro rasgo de una tradición degenerada consiste en que ha ideado un conjunto de defensas epistemológicas que le permiten evitar el ser puesta en cuestión, o, por lo menos, evitar reconocer que está siendo puesta en cuestión por tradiciones rivales. Esto es, por ejemplo, parte de la degeneración de la astrología moderna, de algunos tipos de pensamiento psicoanalítico y del protestantismo liberal. Cualquier rasgo de cualquier tradición, por tanto, cualquier teoría, cualquier práctica, cualquier creencia puede siempre bajo ciertas condiciones ser puesta en cuestión. La práctica de poner en cuestión, sea dentro de una tradición o entre tradiciones, requiere siempre el contexto de una tradición. Dudar es una actividad más compleja de lo que algunos escépticos han creído. Decirse a uno mismo o a alguien más "duda de todas tus creencias aquí y ahora" sin referencia a algún contexto histórico o autobiográfico no es un sin sentido, pero no es una invitación a la filosofía sino al derrumbe mental o, más bien, a la filosofía como medio de derrumbe mental. Descartes se oculta a si mismo, tal como hemos visto, un background no reconocido de creencias, que tradujo inteligiblemente para él y para otros lo que estaba haciendo. Pero supongamos que él hubiese puesto ese background en cuestión también - ¿qué le hubiese sucedido entonces?

No carecemos de pistas, pues tenemos el registro del acceso al derrumbe en la vida de un gran filósofo. "Pues ya he mostrado" escribió Hume.

"que el entendimiento, cuando actúa solo, y de acuerdo a sus más generales principios, se arruina enteramente a sí mismo, y no deja el menor grado de evidencia en proposición alguna, tanto en la filosofía como en la vida cotidiana... La intensa visión de estas centrales contradicciones e imperfecciones en la razón humana me ha impelido de tal manera, y de tal manera ha calentado mi cerebro, que estoy dispuesto a rechazar cualquier creencia y razonamiento, y puedo ver que no hay opinión más probable o más plausible que otra. ¿Dónde estoy, qué soy? ¿De qué causas derivo mi existencia, y a qué condición retornaré? ¿De quién debo cortejar favores, y de quién debo temer la ira? ¿Qué seres me rodean? ¿Sobre quiénes tengo alguna influencia? Me hallo confrontado a todas estas preguntas, y empiezo a concebirme a mi mismo en la más deplorable condición imaginable, rodeado de la más profunda oscuridad y totalmente privado del uso de cada miembro y facultad"3.

\footnotetext{
${ }^{3}$ David Hume, Treatise of Human Nature, ed. Selby-Bigge, Londres: Oxford University Press, Libro I. Iv, viii, pp. 267-269.
} 
Podemos notar tres rasgos sobresalientes en las lastimeras quejas de Hume. Primero, al igual que Descartes, ha establecido un estándar para la fundamentación de sus creencias que es imposible de lograr; por lo tanto, todas las creencias se desploman por igual. No ha preguntado si es que puede encontrar buenas razones para preferir, con respecto al mejor criterio de razón y verdad disponible, alguna entre otras del limitado rango de posibles creencias al que se enfrenta en su particular situación cultural. Segundo, ha rechazado en consecuencia cualquier respuesta o posibilidad de respuesta acerca de aquellas preguntas que, según Bettelheim, subyacen a la totalidad de la empresa narrativa en la niñez temprana. Ciertamente existe la más sorprendente e iluminadora correspondencia entre las preguntas que Bettelheim atribuye al niño y las preguntas elaboradas por el adulto, aunque desesperado, Hume. Pues Hume, dado su radical empirismo, ha perdido cualquier medio de hacerse a él -o a otros- inteligible para si mismo, y ni hablar de para los otros. Su mismo escepticismo se vuelve ininteligible.

Hay quizás un mundo posible en el cual "empirismo" habriase vuelto el nombre de una dolencia mental, mientras que "paranoia" sería el nombre de una bien acreditada teoría del conocimiento. En este mundo, los empiristas serían consistentes e inflexibles - a diferencia de Hume-, y por tanto carecerian de medio alguno para ordenar su experiencia de las otras personas o de la naturaleza. Ni siquiera un conocimiento de la lógica formal los ayudaría; pues hasta que ellos sepan cómo ordenar sus experiencias no poseerán ni oraciones que formalizar ni razones para elegir formalizarlas de una manera en vez de otra. Ciertamente, su mundo estaría reducido a aquel caos 92 que Bettelheim percibe en el niño al inicio de la fase edípica. El empirismo no llevaría a la sofisticación sino a la regresión. La paranoia, por contraste, proveería de considerables recursos para vivir en el mundo. Las máximas empiristas como "cree sólo lo que pueda basarse en la experiencia sensible" o la Navaja de Ockham, nos dejarian desprovistos de toda generalización y por lo tanto de cualquier actitud hacia el futuro (o hacia el pasado). Nos aislarían en un presente sin contenido. Pero las máximas paranoides "interpreta todo lo que sucede como el resultado de la envidiosa malicia" y "todos y todo te defraudarán" son constantemente corroboradas por aquellos que las adoptan. Hume no puede responder a la pregunta: "¿qué seres me rodean?" Pero Kafka sabe muy bien la respuesta a esta pregunta: "De hecho el reloj tiene una cierta relación personal hacia mi, como muchas cosas en la habitación. salvo que ahora, particularmente desde que noté - o más bien desde que se me hizo notar... ellas parecen haber empezado a darme la espalda, sobre todo el calendario... últimamente es como si ellas se hubiesen metamorfoseado. O se muestra absolutamente incomunicativo -por ejemplo, buscas su consejo, acudes a él, pero lo único que dice es 'Celebración de la Reforma'- lo cual probablemente tiene un profundo significado, pero ¿quién puede descubrirlo?- o, por el contrario, se muestra desagradablemente irónico"4.

De esta manera, en este mundo posible se hablaría de la enfermedad de Hume y de la teoría del conocimiento de Kafka. ¿Es este mundo posible tan diferente del

${ }^{4}$ Carta a su hermana Valli, en: I Am a Memory Come Alive, ed. Nahum N. Glatzer. Nueva York: Schocken Brooks, 1974, p. 235. 
que nosotros habitamos? Lo que nos lleva a separar por lo menos algunos tipos de comportamiento mental de comportamientos ordinarios, sanos, es que ellos presuponen $e$ incorporan modos de interpretar el mundo natural y social que son radicalmente discordantes con nuestros modos de interpretación habituales y, como nosotros los consideramos, justificados. Esto es, ciertos tipos de dolencia mental parecen presuponer teorías rivales del conocimiento. Inversamente, toda teoria del conocimiento nos ofrece esquemas para aceptar algunas interpretaciones del mundo natural y social en vez de otras. Como Hamlet descubrió tempranamente, las categorías de la psiquiatría y de la epistemología deben ser en alguna medida interdefinibles.

III

Lo que he estado intentado mostrar es un número de conexiones conceptuales que enlazan nociones tales como las de una crisis epistemológica, una narrativa, una tradición, la ciencia natural, el escepticismo y la locura. Hay un grupo de controversias recientes en las cuales las conexiones entre esos conceptos se han vuelto un tema central. Me refiero, obviamente, a los debates que se originaron de la confrontación entre la filosofia de la ciencia de Thomas Kuhn y los puntos de vista de aquellos filósofos de la ciencia que de una u otra manera son los herederos de Sir Karl Popper. No es sorprendente por lo tanto que las posiciones que he tomado deberian implicar conclusiones acerca de aquellas controversias, conclusiones que no son completamente las mismas que aquellas de los grandes participantes. Es quizás porque los conceptos que he examinado -como aquellos de crisis epistemológica y de conflicto con la tradición- han provisto el background en gran medida no examinado de los recientes debates, cuya clasificación puede de hecho ayudar a resolver algunas de las cuestiones. Quiero argüir en particular que las posiciones de algunos de los más recalcitrantes antagonistas -notablemente Thomas Kuhn e Imre Lakatos- pueden verse converger una vez que son enmendadas en posturas hacia las cuales los propios protagonistas se han movido en la sucesiva reformulación de sus posiciones.

Sin embargo, una nueva conclusión muy chocante emergerá también. Pues quiero reforzar mi tesis de que la narrativa dramática es la forma crucial de la comprensión de la acción humana y quiero argumentar que la ciencia natural puede ser una forma racional de investigación si y sólo si la escritura de una narrativa dramática verdadera -esto es, de historia entendida en una manera particular-puede ser una actividad racional. La razón científica resulta estar subordinada a, y ser inteligible sólo en términos de la razón histórica. Y si esto es cierto de las ciencias naturales, a fortiori lo será también de las ciencias sociales.

Es por lo tanto lamentable que todos los cientificos sociales hayan tratado con tanta frecuencia el trabajo de autores tales como Kuhn y Lakatos tal como se presentaron. Los escritos de Kuhn en particular han sido invocados una y otra vez - por un periodo de diez años o más, una obediencia ritual hacia Kuhn parece haber sido casi un requisito en la dirección presidencial de la American Political Science Association para disculpar los fallos teoréticos de la ciencia social. Pero mientras que el trabajo de Kuhn sin crítica -o, para tal caso, el de Popper o Lakatos- representa un desafio a nuestra comprensión, el trabajo ya revisado de Kuhn nos provee de una aplicación iluminadora para las ideas que he estado defendiendo. 
Mi crítica a Kuhn se dividirá en tres partes. En la primera sugeriré que sus formulaciones tempranas de su posición son mucho más radicalmente erróneas de lo que él ha reconocido. Argüiré entonces que el yerro en reconocer el verdadero carácter de los errores en sus formulaciones tempranas lleva a la debilidad de sus posteriores revisiones. Finalmente sugeriré una más adecuada forma de revisión.

Lo que Kuhn originalmente presentó fue una visión de la crisis epistemológica en las ciencias naturales que es esencialmente la misma que la visión cartesiana de la crisis epistemológica en filosofía. Esta visión estaba superpuesta a una visión de la ciencia natural que parece en gran medida deudora de los escritos de Michael Polanyi (en ninguna parte reconoce Kuhn tal deuda). Lo que Polanyi ha mostrado es que toda justificación tiene lugar al interior de una tradición social y que las presiones de tal tradición frecuentemente imponen reglas no reconocidas, por medio de las cuales, piezas de evidencia discrepante o preguntas difíciles son dejadas de lado con el asentimiento tácito de la comunidad científica. Polanyi es el Burke de la filosofía de la ciencia, y pienso en esta analogía con la filosofía política y moral con gran seriedad. Toda mi anterior crítica a Burke se vuelve ahora relevante para la crítica de Polanyi. Éste, como Burke, entiende la tradición como esencialmente conservadora y esencialmente unitaria. (Paul Feyerabend -a primera vista tan diferente de Polanyi- coincide con Polanyi en su comprensión de la tradición. Y, es precisamente dado que él entiende asi la tradición científica, que él la rechaza y se convierte en el Emerson de la filosofía de la ciencia; no "a todo hombre su propio Jesús", sino "a todo hombre su propio Galileo"). Él no ve la omnipresencia del conflicto -algunas 94 veces latente- dentro de tradiciones vivientes. Debido a esto, alguien que adoptase la visión de Polanyi encontraría muy dificil explicar cómo puede hacerse una transición de una tradición a otra o cómo una tradición que ha caído en incoherencia puede ser reconstruida. Puesto que la razón opera, según Polanyi, sólo dentro de tradiciones y comunidades, tal transición o reconstrucción no podría ser obra de la razón. Habría algún tipo de salto a la oscuridad.

Polanyi no lleva su argumento hasta este punto. Pero lo que es una dificultad principal en la posición de Polanyi, fue presentado por Kuhn como si fuese incluso un descubrimiento. Kuhn ciertamente reconoce totalmente hasta qué punto una tradición científica puede volverse incoherente. Y él debe tener (junto con Feyerabend) todo el crédito por reconocer de manera original el significado y carácter de la inconmensurabilidad. Pero las conclusiones que él extrae, a saber, que "las visiones de los que proponen diversos paradigmas seguramente no hacen completo contacto la una con la otra" y que la transición de un paradigma a otro requiere una "experiencia de conversión" no se sigue de sus premisas concernientes a la inconmensurabilidad. Esta última tiene tres aspectos: quienes suscriben paradigmas rivales durante una revolución clentífica están en desacuerdo acerca de qué conjunto de problemas provee el test para un paradigma exitoso en una situación cientifica particular; sus teorías incorporan conceptos muy diferentes; y ellos "ven diferentes cosas cuando miran desde el mismo punto en la misma dirección". Kuhn concluye que "dado que esta es una transición entre inconmensurables" la transición no puede ser hecha paso por paso, él usa la expresión "cambio de Gestalt" así como "experiencia de conversión". Lo importante es que la manera como Kuhn ve la transi- 
ción requiere de una premisa adicional. No sólo los adherentes de paradigmas rivales están en desacuerdo, sino que toda área relevante de racionalidad es invadida por tal desacuerdo. No se trata sólo de que la inconmensurabilidad esté presente en sus tres aspectos, sino que aparentemente la racionalidad no puede estar presente de otra forma. Ahora bien, esta premisa adicional ciertamente se seguiria de la posición de Polanyi si se entiende que la posición de Kuhn presupone algo como la de Polanyi. Entonces las tempranas formulaciones de Kuhn se vuelven también inteligibles, así como las acusaciones de irracionalismo de sus críticos, acusaciones que Kuhn profesa no entender.

¿Qué se sigue de la posición de Kuhn asi formulada? Que las revoluciones científicas son crisis epistemológicas entendidas de una manera cartesiana. Todo es puesto en cuestión simultáneamente. No hay continuidad racional entre la situación en el tiempo inmediatamente precedente a la crisis y cualquier situación que le siga. Para tal crisis el lenguaje de la conversión evangélica sería ciertamente apropiado. Podemos empezar a hablar con la voz de Pascal, lamentando que el más alto logro de la razón sea aprender lo que la razón no puede lograr. Pero ciertamente, como ya hemos visto, la visión cartesiana de la crisis epistemológica es falsa; no puede darse el caso que todo sea puesto en cuestión simultáneamente. Eso ciertamente acarrearía grandes e ininteligibles lagunas no sólo en la historia de las prácticas (como la de las ciencias naturales) sino también en las biografías personales de los científicos.

Es más, Kuhn no distingue entre dos tipos de experiencia de transición. La experiencia que él está describiendo parece ser la de la persona que, habiendo sido perfectamente educada en prácticas definidas y formada por un paradigma, ha de realizar la transición a una forma de práctica científica definida y formada por algún paradigma radicalmente diferente. De este tipo de persona bien puede ser en ocasiones verdadero lo que Kuhn afirma. Pero tal científico está siendo invitado a hacer una transición que ya ha sido hecha por otros: la misma caracterización de su situación presupone que el nuevo paradigma ya se halla operativo mientras que el antiguo aún conserva algún poder. ¿Pero qué hay del tipo diferente de transición hecha por aquellos científicos que por primera vez inventaron o descubrieron el nuevo paradigma? Aquí las divergencias de Kuhn respecto de Polanyi deberian haberlo salvado de su original conclusión derivada de Polanyi. Pues Kuhn reconoce total y concienzudamente cómo las tradiciones caen en incoherencias. Lo que algunos, por lo menos, de aquellos que están educados en tal tradición pueden llegar a reconocer es la brecha entre sus propios ideales epistemológicos y sus prácticas reales. De aquellos que reconocen esto, algunos pueden tender hacia el escepticismo y algunos hacia el instrumentalismo. Esto, tal como hemos visto, caracterizó la ciencia de la edad media tardía y del siglo dieciséis.

Lo que un genio científico como Galileo logra en esta transición no es sólo una nueva manera de entender la naturaleza, sino también, e inseparablemente, una nueva manera de comprender la manera en que la antigua ciencia comprendía la naturaleza. Esto se debe a que sólo desde el punto de vista de la nueva ciencia se puede caracterizar de tal modo la falta de adecuación de la antigua ciencia, que la nueva ciencia resulte ser más adecuada. Es desde el punto de vista de la nueva ciencia que se reestablecen las continuidades de la historia narrativa. 
Ciertamente, Kuhn ha modificado constantemente sus formulaciones tempranas y, en cierta medida, su posición. En particular, ha señalado enérgicamente a algunos de sus críticos que son ellos quienes le imputan haber sostenido que las revoluciones cientificas son acontecimientos no racionales o irracionales, conclusión que él mismo jamás extrajo. Su propia posición es "que, si la historia o cualquier otra disciplina empírica nos lleva a creer que el desarrollo de la ciencia depende esencialmente de comportamientos que previamente considerábamos irracionales, entonces no deberiamos concluir que la ciencia es irracional, sino que nuestra noción de racionalidad necesita de ciertos ajustes".

Feyerabend, sin embargo, parte de las mismas premisas que Kuhn, y extrae por sí mismo la conclusión que Kuhn rechaza. Y con seguridad si las revoluciones científicas fuesen como Kuhn las describe, si no tuvieran más que los rasgos de inconmensurabilidad, Feyerabend estaria en lo cierto. De modo que si Kuhn necesita, como él mismo dice, "ajustar" la noción de racionalidad, debe encontrar signos de racionalidad en algunos rasgos de las revoluciones científicas a los que aún no ha prestado atención. ¿Existen tales rasgos? Ciertamente, pero pertenecen precisamente a la historia de esos episodios. Es más racional aceptar una teoria o paradigma y rechazar a su predecesora cuando la nueva nos brinda un punto de vista desde el cual la aceptación, la historia de vida y el rechazo de la teoría o paradigma anterior pueden ser reinterpretados en una narrativa histórica más inteligible que antes. La comprensión del concepto de superioridad de una teoría física ante otra requiere una comprensión previa del concepto de superioridad de una narrativa histórica sobre otra. La 96 teoría de la racionalidad científica debe estar inserta en una filosofía de la historia.

Lo que sobrevive de un paradigma a otro son ideales epistemológicos y junto con ellos una comprensión de lo que constituye el progreso de la vida intelectual. La visión de Descartes de su propia crisis epistemológica fue posible gracias a la habilidad de Descartes de reinterpretar su propia historia, de vivir su vida como una narrativa inserta en una historia, habilidad que el propio Descartes no podía reconocer sin falsear su propia visión de las crisis epistemológicas, de la misma manera que Kuhn y Feyerabend reinterpretan la historia de las crisis epistemológicas como momentos de casi total discontinuidad, sin notar la continuidad histórica que hace que sus propias narrativas sean inteligibles. Una posición muy similar a esta, que yo he desarrollado a través de una crítica a Kuhn, fue alcanzada por Lakatos al alejarse de las posiciones iniciales de Popper.

Si Polanyi es el Burke de la filosofia de la ciencia y Feyerabend el Emerson, entonces Popper mismo o al menos sus discípulos heredan el rol de J. S. Mill - como ya notara Feyerabend. La verdad se logra a través de libre choque de opiniones. La lógica de las ciencias morales ha de ser reemplazada por la Logik der Forschung ${ }^{5}$. Donde Burke ve el razonamiento sólo en el contexto de la tradición y Feyerabend ve a la tradición como meramente represora del individuo, Popper ha intentado acertada-

${ }^{5}$ Lógica de la investigación (N. T.). 
mente darle algún sentido a la noción de tradición racional. Lo que estorbó sus intentos fue su insistencia en reemplazar la falsa metodología de la inducción por una nueva metodología. La historia del pensamiento de Popper y el de sus más preclaros seguidores fue por muchos años la historia de los sucesivos intentos de reemplazar el falsacionismo original de Popper por alguna versión más adecuada. cada una de las cuales cayó presa de los contraejemplos de la historia de la ciencia. Desde un cierto punto de vista el verdadero heredero de esos intentos es Feyerabend; es él quien formuló la tesis general de que tales intentos estaban condenados al fracaso. No hay un conjunto de reglas acerca de cómo la ciencia debe proceder, y todos los intentos por descubrir ese conjunto de reglas zozobran al enfrentarse a la historia de la ciencia. Pero cuando Lakatos finalmente aceptó esto se desplazó hacia una nueva postura.

En 1968, cuando aún era un popperiano relativamente conservador, Lakatos escribió: "lo que se evalúa es en realidad un conjunto de teorías y no una teoría aislada". Desarrolló esta idea hasta llegar a la noción de programa de investigación. La noción de programa de investigación está orientada hacia el futuro y hay por lo tanto una tensión entre el uso de Lakatos de esta noción y su reconocimiento de que un conjunto de teorías sólo puede ser evaluado retrospectivamente. En otras palabras, lo que se evalúa es siempre una historia: pues no es sólo un conjunto de teorías lo que se evalúa، sino un conjunto que mantiene determinadas relaciones internas a través del tiempo. Lo que consideramos como una teoria aislada es "una entidad en desarrollo y crecimiento, que no puede ser considerada como una estructura estática"o Consideremos, por ejemplo, la teoría cinética de los gases. Si leemos los textos científicos de cualquier época encontraremos que se presenta una visión totalmente ahistórica de la teoría. Pero si leemos los sucesivos textos científicos nos daremos cuenta no sólo que la teoría cinética de 1857 no era la de 1845 , y que la teoría cinética de 1901 no era ni la de 1857 ni la de 1965. Veremos también que cada etapa de la teoria lleva la marca de su historia previa, de una serie de confrontaciones con evidencia que la confirma o que es anómala, con otras teorias y puntos de vista metafísicos, etc. La teoria cinética no solamente tiene una hiștoria, sino que es una historia, y evaluarla es evaluar cómo se ha conducido a lo largo de una variedad de confrontaciones. ¿Cuáles de ellas han sido derrotas, cuáles victorias, cuáles una mezcla de ambas y cuáles no se dejan clasificar bajo ninguno de esos encabezados? Evaluar una teoría, asi como evaluar un conjunto de teorias, o un programa de investigación lakatiano, es justamente escribir esa historia, la narrativa de las victorias y derrotas.

Esto es lo que Lakatos reconoció en su artículo "La historia de la ciencia y sus reconstrucciones racionales ${ }^{7}$. Las metodologías han de ser evaluadas por la medida en que satisfacen criterios historiográficos; la mejor metodología científica es aquella

\footnotetext{
- Richard M. Burian. "More than a Marriage of Convenience. On the Inextrincability of History and Philosophy of Science", inédito, p. 38.

7 I. Lakatos. "History of Science and Rational Reconstructions", en: Boston Studies in the Philosophy of Science, Vol. III, Roger C. Buch y Robert S. Cohen (ed.). Dordrecht Holland: D. Reidel Publishing Co., 1974.
} 
que es capaz de brindar la mejor reconstrucción racional de la historia de la ciencia, y para diferentes episodios distintas metodologias pueden ser exitosas. Pero al no hablar de historia, sino de reconstrucciones racionales, Lakatos no ha exorcizado aún los fantasmas de la vieja creencia popperiana en la metodologia: simplemente se ha preparado para considerar a la reconstrucción racional como una mera "caricatura" de la historia real. Pero así como es de gran importancia que nuestras historias sean verdaderas, así también es importante que nuestras teorias científicas hagan de la verdad una de sus metas.

Es interesante y quizás extraño que Kuhn insista, contra Lakatos, en la verdad de la historia (él acusa a Lakatos de reemplazar la verdadera historia por "filosofía fabricando ejemplos"), pero que aún así insista en negarle a las ciencias naturales cualquier noción de verdad que no sea la relacionada con solucionar enigmas y acertar predicciones. En particular, niega que una teoría científica pueda incorporar una ontología verdadera, que pueda brindar una correcta representación de "lo que realmente hay". "No hay forma de reconstruir frases como 'lo que realmente hay' independientemente de una teoría: la noción de correspondencia entre la ontología de una teoría y su contraparte 'real' me parece ahora en principio ilusoria" ${ }^{8}$.

Esto es bastante extraño, porque la ciencia nos ha mostrado decisivamente que algunos enunciados de existencia son falsos justamente porque las entidades en cuestión no existen realmente - más allá de lo que cualquier teoría diga. El atomismo de Epicuro no es verdadero, no existen los humores, no existe nada con 98 peso negativo, ni el flogisto, las brujas, ni los dragones. Pero otros enunciados han sobrevivido excepcionalmente bien a través de una sucesión de posturas teoréticas particulares: las moléculas, las células y los electrones. Clertamente nuestras creencias acerca de las moléculas, las células y los electrones no son las que una vez fueron. Pero Kuhn se pondría en una posición bastante curiosa si sostuviera que éste es un motivo para negar que algunos enunciados de existencia siguen teniendo excelente garantía mientras que otros no.

Lo que preocupa a Kuhn es otra cosa: "en algunos aspectos importantes, aunque no en todos, la teoría general de la relatividad de Einstein está más cerca de la mecánica de Aristóteles de lo que ambas están de la teoria newtoniana"9. Concluye, por tanto, que la superioridad de Einstein sobre Newton está en la resolución de enigmas y no en su aproximación a una ontología verdadera. Pero lo que la ontología de Einstein nos permite entender es por qué desde el punto de vista de una aproximación a la verdad, la mecánica newtoniana es superior a la aristotélica. Pues la mecánica aristotélica, tal como se desarrolló y como finalmente llegó a colapsar, no nos permitiría el paso hacia la teoría especial; como quiera que sea reformulada, los problemas aristotélicos acerca del tiempo jamás llevarán hacia los problemas para los cuales la teoría especial de la relatividad es la respuesta. Una historia que vaya directamente desde Aristóteles hacia la física relativista no es una historia imaginable.

\footnotetext{
${ }^{8}$ Thomas Kunn, The Structure of Scientific Revolutions, 2da ed., Chicago: University of Chicago Press. 1970. p. 206.

9 Ibid.. pp. 206-207.
} 
Lo que Kuhn no toma en cuenta al negar la verdad ontológica es la manera en que el progreso hacia la verdad en las diferentes ciencias es tal que han de converger. El fácil reduccionismo de algunos programas cientificos positivistas es desorientador, pero el rechazo de tal reduccionismo no debe cegarnos a la necesaria convergencia de la física, la química y la biología. Si no tuviera importancia la verdad ontológica. nuestra exigencia de una relación coherente y convergente entre todas las ciencias seria ininteligible.

El punto de vista de Kunn, ciertamente, es atractivo simplemente porque parece consistente con el falibilismo que todos tenemos razones para aceptar. Quizás la física einsteiniana será superada algún día tal como lo fue la física newtoniana: quizás, como suele sugerir Lakatos en sus más coloridos momentos retóricos, toda nuestras creencias científicas son, han sido y serán siempre falsas. Pero parece que un presupuesto de la manera en que hacemos ciencia natural es que el falibilismo debe ser consistente con el ideal regulativo de una aproximación hacia una visión verdadera del orden real de las cosas, y no viceversa. Si es asi, Kant está básicamente en lo correcto; la noción de un orden subyacente -el tipo de orden que esperariamos si el dios ingenioso y no malicioso de Einstein y Newton hubiese creado el universo- es una idea regulativa de la fisica. No necesitamos entender esta noción tal como lo hizo Kant, y nuestras creencias antiteológicas pueden hacer que nos resulte incómodo adoptarla así. Pero quizás en este punto la incomodidad es signo de progreso filosófico.

Estoy sugiriendo, entonces, que la mejor visión que podemos dar de por qué algunas teorias científicas son mejores que otras presupone la posibilidad de construir una narrativa dramática inteligible que pueda pretender verdad histórica, en la que tales teorías son protagonistas de sucesivos episodios. Es sólo porque podemos construir mejores y peores historias de este tipo, historias que pueden ser comparadas unas con otras, que podemos también comparar teorias de manera racional. La física presupone la historia, y una historia de tal naturaleza que invoque los conceptos de tradición, inteligibilidad y crisis epistemológica que he defendido. Es esto lo que nos permite entender por qué el punto de vista de Kuhn sobre las revoluciones científicas puede ser rescatado de los cargos de irracionalismo levantados por Lakatos, y por qué los escritos finales de Lakatos pueden ser rescatados de los cargos de evasión de la historia que levanta Kuhn. Sin este background, las revoluciones cientificas se vuelven episodios ininteligibles: Kuhn se vuelve lo que en esencia Lakatos lo acusa de ser, el Kafka de la historia de la ciencia. No sorprende que Kuhn, por su parte, sintiese que Lakatos no era un historiador de la ciencia, sino un escritor de novelas históricas.

Ahora es posible articular una tesis final. Cuando las conexiones entre narrativa y tradición de un lado. y teoría y método de otro, se pierden de vista, la filosofía de la ciencia se enreda en problemas insolubles. Cualquier conjunto finito de observaciones es compatible con cualquiera de las infinitas generalizaciones posibles. Cualquier intento de mostrar la racionalidad de la ciencia estableciendo un conjunto justificable de reglas que vinculen las observaciones y las generalizaciones, está condenado al fracaso. Esto vale, como lo muestra la historia de la escuela popperiana, tanto para el falsacionismo como para cualquier versión del positivismo. Es válido, como lo mues- 
tra la historia de los trabajos de Carnap, sin importar cuánto se progrese en las estructuras particulares y detalladas de la inferencia científica. Es sólo cuando las teorias son ubicadas en su historia, sólo cuando tenemos en cuenta las demandas de justificación en contextos de tipo histórico sumamente particulares, que nos liberamos tanto del dogmatismo como de la capitulación del escepticismo. Resulta, por tanto, que el programa que ha dominado la filosofía de la ciencia desde el siglo XVIII en adelante, combinación de empirismo y ciencia natural, está condenado a sucumbir, en el peor de los casos en el irracionalismo o, con suerte, en una serie de programas empiristas sucesivamente debilitados cuya fuerza conductora es un profundo deseo de no verse forzados a conclusiones irracionalistas. El mal de Hume es, sin embargo, incurable y, en último término, fatal, y ni siquiera el backgammon (ni aún ese tipo de filosofía analítica que es frecuentemente el backgammon de los filósofos profesionales) puede dilatar indefinidamente esta agonía. Es, después de todo. Vico, y no Descartes ni Hume, el que resultó tener la visión correcta de la relación entre la historia y la fisica.

Traducción: Gonzalo Cobo. 